\title{
Is there a deficit of engineering principle as a result of the UK skills gap?
}

\author{
Sam Edwards. IEng, MIET
}

University of Huddersfield, Queensgate, Huddersfield, HD1 3DH

A R T I C LE I N F O

Article history:

Received 18 October 2020

Received in revised form 14

February 2021

Accepted 07 April 2021

\section{Keywords:}

Engineering

Manufacturing

Skills Gap

Apprenticeships

Graduate

\section{A B S T R A C T}

It is widely acknowledged that the UK skills gap in engineering and especially manufacturing is impacting national manufacturing in a post millennium Britain. This study explores how the engineering skills shortage, from both a practical and theoretical standpoint, is impacting upon the availability and utilisation of engineering labour in addition to considering what appear to be shortcomings in education and training with respect of in meeting the skills gap. The research conducted in this study aims to make recommendations as to how the educational system and workplace training can be enhanced for engineering trainee's so as to better cater for the skills required in industry, and therefore enabling greater future prosperity within engineering and manufacturing. This study utilised a mixed method approach to data collection, using questionnaires in order to analyse and identify attitudes of personnel working within engineering and manufacturing sectors. Such attitudes relate to self-esteem and regard for qualified and skilled colleagues, which is dependent on their ability and proficiency. Proficiency is then linked to the chosen route of education and training. Upon completion of the study the research revealed a multitude of attitudes direct from industry. However, due to the small pool size of individuals involved with the survey, a definitive outcome could not be distinguished, but rather a fundamental understanding which offers a premise for further study into the topic in future. Suggestions attained from the workplace survey direct the outcomes to three suggested routes for increasing engineering workforce quality and reducing skills shortage:

- Increased availability of apprenticeships.

- Workplace-relevant and practical focused undergraduate education.

- Trained Engineers with a balance of practical, technical and analytical skills. 


\section{Introduction}

The Oxford Learner's Dictionary defines the noun "Engineer" as "a person whose job involves designing and building engines, machines, roads, bridges" (Oxford University Press, 2019). Likewise, the Cambridge Dictionary's definition of the word "Engineer" is "a person whose job is to design or build machines, engines,

or electrical equipment, or things such as roads, railways, or bridges, using scientific principles" (Cambridge University Press, 2019). But in the modern world, the definition of engineer is heavily weighted by personal opinion and does not always coincide with the industry role - for example, the following job titles are industry roles available on indeed.co.uk (2020):

- Senior Deskside Engineer

- Trainee Telecom Engineer

- Coffee Service Engineer

- Specialist Fibre Engineer

- Motor Claims Engineer

"Unlike some countries, where the designation is better defined, the situation in the UK remains liberal and self-regulated" (Matthews, 2012, p.1.). The production of this statement by the Institute of Mechanical Engineers showing recognition for a most fundamental part of engineering, gives validity to the alarming state of disarray that has overcome the engineering profession in the UK. To attribute this to one factor would be both ignorant and pointless, being that when explored, the subject matter can be found to be rather more complex than it was first understood to be. Though there are a multitude of opinions in existence that claim to understand the origins and the reasons behind the skills shortage in the UK, fundamentally there is no key evidence to support one definitive reason as to why the industry is battling a skills gap, but rather multiple complex elements that all result in the shortage. One undeniable fact is that there is a skills shortage to the detriment of the UK manufacturing industry, with numerous reports and studies to support this.

Until the present time, the quality of engineering staff has not been investigated in depth or detail. Additionally, the acknowledgment and understanding of the proven skills gap has not been considered when understanding the effects of reforms in UK manufacturing on the trainee engineers. When defining the title of this study 'Is there a deficit of engineering principle as a result of the UK skills gap?', this is in reference to a perceived lack of adequate skills - whether this be qualifications or experience - and how the UK skills gap has influenced this. Although rarely discussed, this lack of quality in engineering is known to exist - the Royal Academy of Engineering (2018) states that "The primary school system almost extinguishes any opportunities for students to flourish as engineers and in secondary schools the qualification systems force early specialisation." These systems mean that teachers unintentionally discourage potential engineers through the way they teach science, mathematics, and design and technology. Reports from The Royal Academy of Engineering (The Royal Academy of Engineering, $2006,2007,2010$ ) have given prominence to the urgency of addressing change within the undergraduate education system for engineers. Although these reports were published in the decade between 2000 and 2010 , an additional report published by the same institute in 2012 revealed that many of these changes were still to be implemented. However, this study illustrated that changes already made within the education of undergraduate engineers had yielded positive results, and these can be seen in Figure 1.

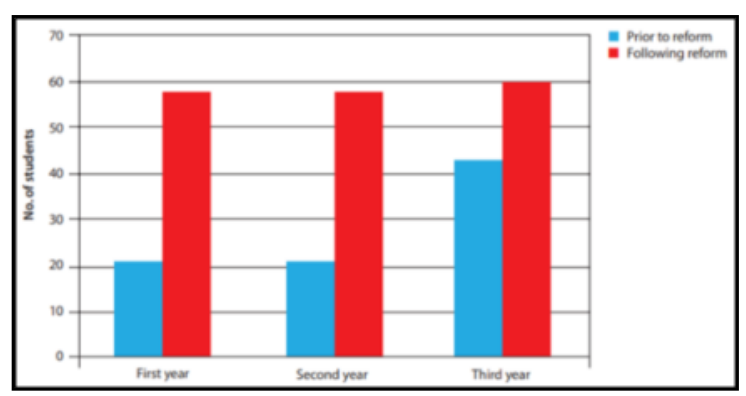

Figure 1. Percentage of students achieving the two highest attainment classifications. RAENG. (2012)

\section{The current state of engineering in the UK}

In 2018, the UK government indicated its desire for a move to an hourglass economy; which would be the most suitable structure to aid in continual growth of the UK economy. Accounting for a world becoming more digitalized and automated, this eco structure is believed to allow the manufacturing industry to remain competitive and productive in a $21^{\text {st }}$ century post-Brexit economic climate. Figure 2 visually demonstrates the hourglass economy structure, which aims to reduce the mid-skilled labour whilst boosting the demand for high and low-level skilled individuals. Engineering UK (2018) specifies that the net requirement projections 
from Working Futures 2014-2024 indicate that by $2024,54.1 \%$ of the manufacturing workforce will require Level 4 qualifications as a minimum.

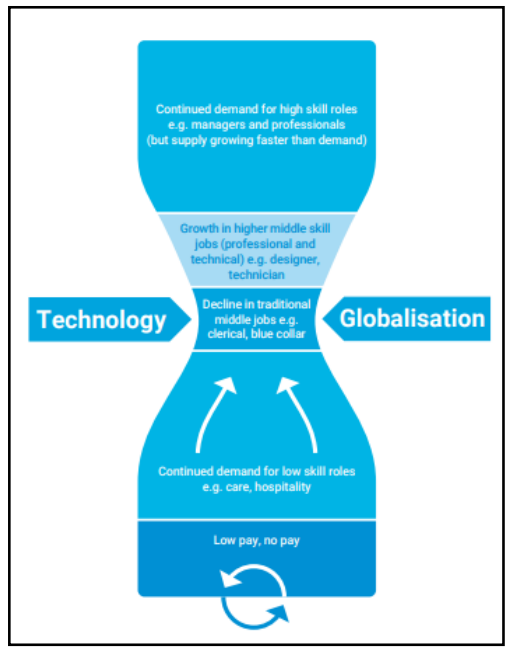

Figure 1. Hourglass Model. Engineering UK (2018).

The same report also states that 203,000 people with Level 3 engineering skills will be required each year to meet demand through to 2024. Crossreferenced with the directional change of the economic structure and the shortfall of between 37,000 to 59,000 engineers per year, the question of how to not only entice, but also suitably educate new engineers, has to be posed.

Traditionally in engineering, the UK mainly competed with countries such as the USA and Germany, who held a good reputation worldwide for producing high quality engineered products at a cost. Now that countries like India and China manufacture products of medium quality at an affordable cost, whilst countries like Germany and the USA are still producing high quality products at a high cost, the UK manufacturing industry has lost the edge it once had. The Manufacturer (2019) indicates that although the UK remains in the top ten countries for manufacturing output, its position has declined over the years falling from seventh place in 2006 to ninth in 2016. Figure 5 demonstrates that as of 2006, employment in manufacturing was at its lowest since 1973, indicating the UK manufacturing industry is burdened with a lack of demand. As businesses and the UK government attempt to improve and increase product output, this will increase the demand for engineers. Data shown below in figure 3 indicates reforms are required to aid the manufacturing industry in acquiring the desired quantity of employees.

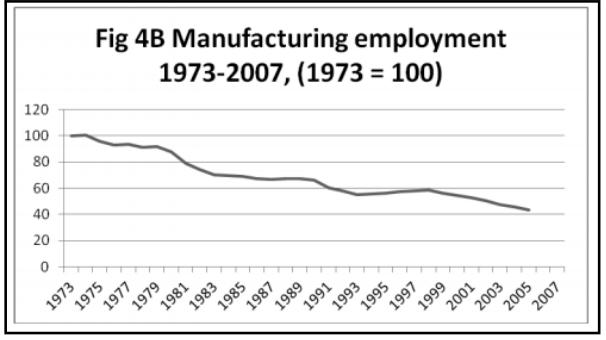

Figure 2. Manufacturing employment 1973-2007. Kitson, M. Michie, J. (2014. P, 13).

\section{UK political climate (1945-2020)}

We will now turn our attention to the UK economic situation pre-1980s, specifically the years between 1945 and 1980. This period is important as it influenced the most defining decade of recent history of UK manufacturing -- the 1980 s itself and requires understanding to gain knowledge of why the UK made such significant changes to its industries.

After WWII, the UK was placed in a high debt situation. This debt was a result of the USA initiative entitled the Marshal Plan, providing \$15 billion of aid to Western Europe with the intention of rebuilding the industry, infrastructure and cities within a four-year time period. History.com (2009) states "The Marshall Plan provided aid to the recipients essentially on a per capita basis, with larger amounts given to major industrial powers, such as West Germany, France and Great Britain.” As dire as this situation appears, the world required rebuilding; western countries such as the UK were able to exploit their advanced knowledge of engineering principles to increase their exported products. This demand for exports reduced unemployment within the UK which remained low for around 22 years before it began to slowly increase. Identified as the 'Global Economic Boom', this benefitted strong European powers such as Western Germany, France and Great Britain (UK).

As the 1970's unfolded, unemployment in the UK more than doubled from around 2.3\% in 1970 to around $5.9 \%$ in 1980. Furthermore, the inflation rate increased by around 15\% between 1970 and 1975, whilst UK GDP reduced. Common knowledge states this uncertainty and economic issue was as a result of the collapsing mining industry. This data is displayed in figure 4 . 


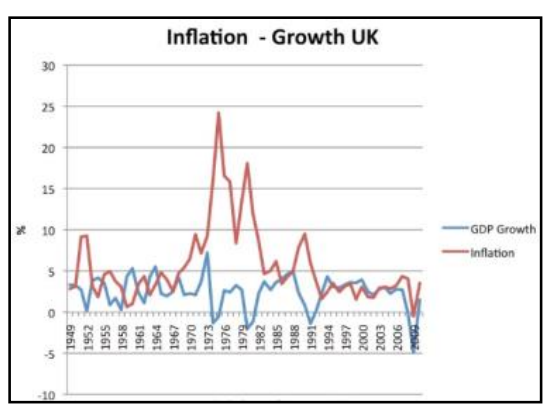

Figure 3. UK national Debt chart. Pettinger, T. (2017).

To reduce government overheads and encourage free market growth of the UK economy, state owned companies were sold off. Observing this list of companies privatised between 1979 and 1990, an understanding can be gained as to how this impacted the subject matter at hand. The Telegraph (2013) and OpenSecrets.org (2020) specify that the following government-owned companies were privatised. Table 1 below indicates that the majority of the companies that were privatised were engineering and manufacturing companies.

\begin{tabular}{|c|c|c|}
\hline Company & $\begin{array}{l}\text { Industry } \\
\text { Sector }\end{array}$ & $\begin{array}{c}\text { Industry } \\
\text { Description }\end{array}$ \\
\hline $\begin{array}{c}\text { British } \\
\text { Petroleum }\end{array}$ & $\begin{array}{c}\text { Energy \& } \\
\text { Natural } \\
\text { Resource }\end{array}$ & Oil \& Gas \\
\hline British Aerospace & $\begin{array}{c}\text { Defence, } \\
\text { Manufacturing }\end{array}$ & $\begin{array}{c}\text { Defence } \\
\text { Aerospace, } \\
\text { Engineering }\end{array}$ \\
\hline Cable \& Wireless & Communications & $\begin{array}{c}\text { Tele- } \\
\text { communications }\end{array}$ \\
\hline $\begin{array}{c}\text { Amersham } \\
\text { International }\end{array}$ & Health & $\begin{array}{c}\text { Pharmaceutical } \\
\text { supplier }\end{array}$ \\
\hline $\begin{array}{c}\text { Associated } \\
\text { British Ports }\end{array}$ & Transportation & Sea services \\
\hline Jaguar & Manufacturing & Engineering \\
\hline $\begin{array}{c}\text { British } \\
\text { Shipbuilders }\end{array}$ & Manufacturing & Engineering \\
\hline British Gas & $\begin{array}{c}\text { Energy \& } \\
\text { Natural } \\
\text { Resource }\end{array}$ & Oil \& Gas \\
\hline British Airways & Transportation & Airline \\
\hline Rolls-Royce & Manufacturing & Engineering \\
\hline BAA & Transportation & Air Transport \\
\hline British Steel & Misc Business & Steel Production \\
\hline
\end{tabular}

Published under Creative Commons Attribution License 4.0 University of Huddersfield Press unipress.hud.ac.uk
This list indicates the majority of the companies privatised were engineering and manufacturing companies. During this era in British history, the country was polarised as a result of the Thatcher reforms and policies, into a north vs south divide. It is important to note that often the Thatcher era is blamed for the demise of the north and manufacturing. Whilst this is not totally correct this era of politics did increase the speed with which the north was de-industrialised - J, Coman (2013) states: "the north suffered the worst of the deep recession and high unemployment of the early years; and it benefited least from the eventual boom of the late 1980s". When the Thatcher government began the closure of what they deemed 'uneconomical' collieries in the UK, this posed the most detriment to the north of England. Figure 5 demonstrates the quantity of collieries and their locations within the UK.

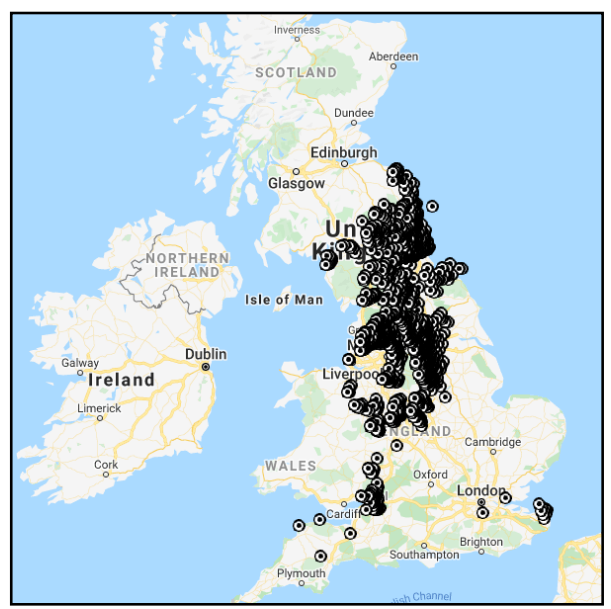

Figure 4. Coal mine locations UK. Northern Mine Research Society. (2020).

The result of these closures was the high unemployment observed in areas of the north such as: Yorkshire, Nottinghamshire, Durham etc. Beatty, C. et al. (2015, p1660) estimate that between 1981 and 2004 around 67,000 male job roles were made redundant. $95 \%$ of these job losses can be directly attributed to the demise of the coal industry.

Additionally, it can be seen in Figure 6, that as the years passed the manufacturing industry significantly reduced, increasing skilled unemployment and reducing demand for engineering skills. This is a clear indication of the 'knock-on effect' the closure of collieries had on the surrounding engineering industry that was being 
used to provide the mining industry.

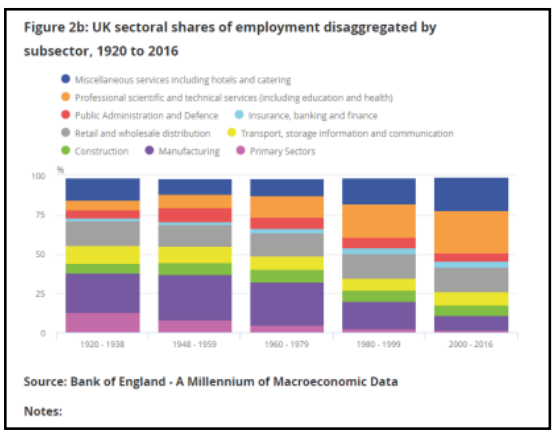

Figure 5. Sectorial employment shares. Office of National Statistics. (2018).

\section{Education Reforms}

Education reforms brought about in the 1980's were centred on the secondary education system within the UK; this level of education provides the fundamentals for any individual in addition to guidance on their future educational routes. Machin and Vignoles (2006) state "More than two thirds of the cohort did not achieve examination success at age 16 and therefore entered on the labour market with no academic qualifications at all. Of course, many of these individuals went on to take vocational qualifications". This statement is supported by the data displayed in figure 7 .

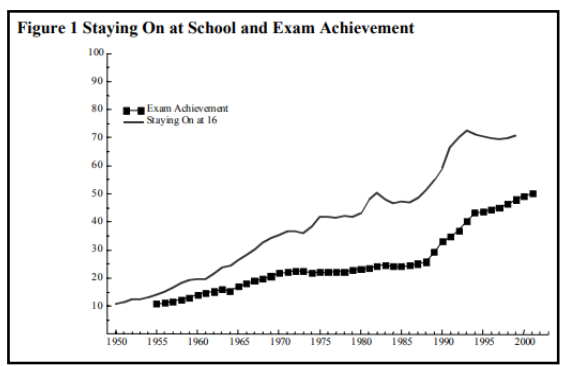

Figure 6. School achievement. Machin, S. Vignoles, A. (2006. P 2).

One major reform introduced was full transparency with regards to student GCSE and A level results. The government implemented league tables for monitoring the success of schools and colleges. A discussion with $\mathrm{M}$, Mavromhales from the University of Huddersfield revealed that whilst league tables had not caused direct issues, the industry consensus from colleagues in secondary education teaching, college education teaching and university education teaching viewed these as a detriment to the quality of education being delivered to students. (M. Mavromhales, personal communication, April 07, 2020).
A mix of mass unemployment and a push for a service-based economy required more academically qualified individuals, causing the apprenticeship system to collapse. The educational system for vocations was multitudinous and did not coincide with its academic counterparts, creating an imbalance in the quality of individuals such as engineers. To aid in tackling this issue, the government introduced the National Vocational Qualification (NVQ) which was aimed at assessing individuals on a competency basis - unfortunately, these qualifications held relatively low value.

\section{Current education}

The 2019 UK Government report promoting apprenticeship schemes clearly states that apprenticeships are real world job opportunities which guarantee apprentices employment - from the day of enrolment. Apprenticeships combine practical training in a job with study. An apprentice will:

- Work alongside experienced staff

- Gain job-specific skills

- Earn a wage and get holiday pay

- Be given time for study related to their role (the equivalent of one day a week)

Furthermore, the government report advises anyone undertaking an apprenticeship is entitled to the hourly pay detailed below in table 2 .

Table 1. Apprentice Pay vs Age. Gov.uk (2019

\begin{tabular}{|l|l|}
\hline Age & Rate \\
\hline $16-18$ & $£ 4.34$ \\
\hline $18-20$ & $£ 6.15$ \\
\hline $21-24$ & $£ 7.70$ \\
\hline 25 and over & $£ 8.21$ \\
\hline
\end{tabular}

As apprenticeships are not based on educational capacity but rather industry demand, it is important that these schemes are appealing for businesses. Traditionally companies would pay the education fees for apprentices; as a result, they received lower wages. However as stated by the UK government in 2020, any business employing an apprentice will only have to pay $5 \%$ of the education fees.

The Graduate route involves performing full-time education through a college before attending a university and then finally attaining a workplace job. There are two forms of graduate schemes; the first is where an individual completes all their education on a full-time basis; the second is where 
an individual can undertake a placement year during their degree. Similar to the apprenticeship schemes, the graduate route also has multiple offerings when it comes to engineering courses. Furthermore, the entry requirements are more stringent than what is required to undertake the same qualifications after completion of an apprenticeship. Additionally, the A level subject requirements do not have to be of a technical nature, but they do have to be STEM related.

\section{Research lacunae}

When researching previous literature for this study, it was discovered that whilst research into the UK engineering skills gap has been conducted and studied in depth with solutions proposed, no institution has investigated the effects of the engineering and manufacturing decline in the UK and how it has impacted the education of young engineers. The main literature cited in this research was the 2018 Engineering UK report in which the skills gap present in the UK engineering industry was widely explored with suggestions proposed to aid in recruiting more individuals into the field. Upon evaluation of this, it was discovered that there was a gap in the research to be explored, specifically around the study of the quality of engineering skills and training.

It can be hypothesised that the reason for this research gap is that there has been a heavy focus on quantity of engineers rather than quality, in an attempt to fill the labour requirements rather than the skill requirements. With this hypothesis proposed, the research conducted for this study attempted to understand the complexities of the skills gap by addressing the political, societal and economic attitudes of the current situation as compared with that before the gap became apparent. Taking an approach which aims to make training and qualifications applicable to present day requirements rather than an outdated system.

\section{Research methodology}

The study utilised a mixed methods approach to gain the relevant information, incorporating qualitative and quantitative data collation techniques such as a workplace survey. Statistical analysis comparing percentages of answers against the response pool size was performed in order to attain numerical data that would validate the information received and allow it to be displayed as visual aids such as line graphs, bar graphs, pie charts etc.
When constructing the workplace survey, a multitude of research question types were utilised, including those that were closed-ended, multiple choice, dichotomous, demographic, rank order scaling, Likert scaling and open-ended. 19 questions were created, as follows:

\section{Please Select Your Age Range.}

Posing this quantitative question allows the researcher to establish the age range of each individual respondent, organising the demographic by age. Furthermore, this question can demonstrate the physical evidence of whether the UK skills gap exists.

\section{Please Specify Gender}

Another demographic question providing the researcher with qualitative data, this question is important in understanding the gender equality dimension of the study area.

\section{Which Term Appears in Your Job Title?}

By filtering the participants into role-specific demographics, an understanding of how relatable the subject matter will be to these individuals can be gained.

\section{Please Indicate Your Educational Route}

This question establishes how the respondent gained their qualifications, highlighting biases present amongst the sample group.

\section{What Qualifications do you Currently Hold?} An open-ended question, allowing an understanding of the qualifications each individual holds. Acquiring this knowledge aids by allowing statistical analysis to be carried out, comparing the individual's current job role with their experience level.

6. Please Indicate Your Experience Range (Years) Quantitative based inquiry allowing the researcher to gain data based on respondent's age. This in turn allows for comparisons to be drawn between an individual's professional experience versus their qualifications versus their current job role.

\section{Do You Currently Hold a Managerial Position?}

A dichotomous question, this simple inquiry will allow the researcher to establish the quantity of senior level individuals within the survey. 
8. Please Indicate Your Preferred Pay Structure. Allows the respondent to select from five pre-set answers all of which were sourced externally. This will allow an understanding of what type of pay structure is most desirable for a career in engineering.

9. Please rank in order of importance (one being the most important) which benefits would be most attractive for a career in engineering?

A rank order scaling question to understand how the benefits which can be found in other industries such as finance, tech etc. appeal to an individual currently within engineering.

10. Please rank in order of importance (one being the most important) which you feel is top priority? Qualification /Experience/Interpersonal skills/Leadership skills

Also a quantitative rank order scaling question, this question is derived purely for the purpose of quantifying elements within this study associated with engineering.

11. What quantification of experience would you assign to an individual to consider them a competent engineer (years)?

This question utilises a multiple-choice method to assign the respondent to a demographic based on an individual's opinion of what constitutes a competent engineer.

\section{How would you rate the education you received post-secondary education?}

Although not directly related to the subject matter of this specific survey, this Likert scale question is designed to give the researcher an understanding of the individual's opinion of the UK educational establishment, post-secondary education.

\section{How experienced do you feel you are for the job} role you currently perform?

Visually, using a slider scale, this question allows participants to indicate an honest opinion of their own experience competency. Utilising a question like this will give a 'current' view of the state of the industry.

\section{How qualified do you feel you are for the job role you currently perform?}

Using a visual Likert slider scale, this question is multi-layered in the information that can be drawn from it. This query allows the researcher a 'current' view of the state of the industry.
15. Are there any changes you would suggest to the post-secondary education system for training engineers within the $U K$ ?

Uses a qualitative approach, incorporating an openended question with a comment box allowing personal opinion to be given. This kind of question will also allow constructive feedback to be incorporated into the conclusion of the report.

16. Do you believe there is a skills gap in your sector within the UK?

This dichotomous question aids in understanding whether the participant agrees with the underlying principle of the subject matter.

\section{Do you believe that there is a deficit of engineering principle as a result of the UK skills gap?}

Question seventeen is used to gain an understanding as to whether the individuals taking part in the survey consider the engineering principle to be lacking as a result of the discussed skills gap.

\section{How severe would you describe the UK skills} gap?

Using a Likert visual slider scale the phrasing of this question is designed to divide the pool size into three demographics: individuals who believe there is a skills gap, individuals who don't believe there is a skills gap and individuals who have no opinion on this. Utilisation of this question allows numerical values to be placed against the quantity of individuals who believe the UK skills gap is severe and detrimental to the state of manufacturing.

\section{How would you define the noun "Engineer"?}

A qualitative style of inquiry utilising a comment box, the final question is arguably the most important posed. This question allows the individuals participating in the survey to give their opinion on what defines a competent engineer.

\section{The survey}

Two UK based manufacturing companies were selected for the survey to take place. Hosted via an online platform provider, the survey was designed to enable respondents to be able to complete it anonymously. With the aim of increasing the response rate, a paper version was available for anyone who did not have access to the online version. 
Table 2. Survey Response Details

\begin{tabular}{|l|l|}
\hline Platform Provider & Survey Monkey \\
\hline Date Performed & $03 / 02 / 2020-17 / 02 / 2020$ \\
\hline Question Quantity & 19 \\
\hline Response Rate & $\begin{array}{l}22 \text { individuals out of est. } 70 \\
\text { employees }\end{array}$ \\
\hline Response Rate\% & Est. 31.5\% \\
\hline $\begin{array}{l}\text { Individual Completion } \\
\text { Rate \% }\end{array}$ & $100 \%$ \\
\hline $\begin{array}{l}\text { Average Completion Time } \\
\text { (Entire survey) }\end{array}$ & 8 minutes 13 seconds \\
\hline $\begin{array}{l}\text { Average Completion Time } \\
\text { (Per question) }\end{array}$ & 41 seconds \\
\hline
\end{tabular}

From Table 3 above, it can be seen that the workplace survey created for this study was engaging, easy to complete and successful when compared with suggestive data from existing survey providers.

The two companies utilised are local to the Yorkshire region of the UK and are both involved in engineering manufacturing. Both businesses are specifically involved in the bespoke manufacturing of complex systems, with one company specifically manufacturing for pharmaceutical clients whilst the other focused on manufacturing automation machinery. Both business operate with a "one off" or "jobbing shop" business model meaning that highly skilled labour is required as many of the manufacturing processes cannot not be automated.

\section{Study limitations}

Due to the originality of the subject matter investigated, it was decided that only two local companies were to be utilised to understand if the subject matter explored is actually an issue within industry and not just an opinion. Consequently, one major limitation became apparent as the study was completed. This was that the overall pool size of total employee's was very small, at only 70 people when this factor is cross referenced with a response rate of $31.5 \%$ we have to conclude that the respondent results were too small to give any definitive answers to the original query. However, this pool's size does not impede the study's intention to understand whether there are issues on which further exploration could be performed.
It is important to understand that the survey created for this study was to assess a small pool of individuals currently in the field, in an attempt to understand the relevance of the topic at hand and whether or not changes are required to ensure there is not a deficit of engineering principle.

\section{Results}

1. Please Select Your Age Range.

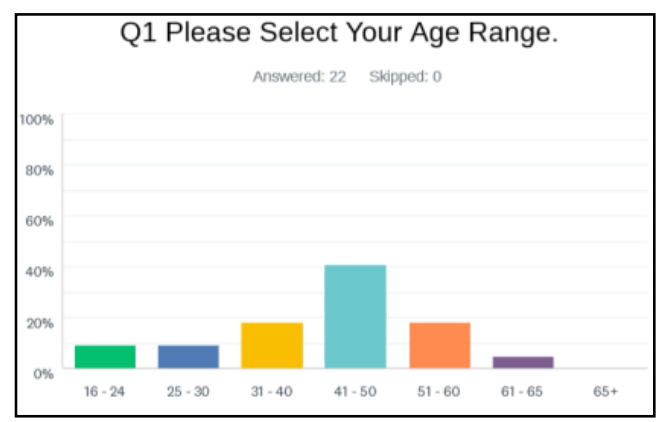

Figure 7. Age Range Vertical Bar Chart

This quantitative demographic question provided the answer to a fundamental element of the study when assessing the existence of the skills gap. Figure 8 demonstrates that the largest employed age range was for individuals within the 41-50 category, whilst the 61-65 category incorporated the lowest employment levels amongst respondents. However, the focus range was the individuals in the younger categories such as 16-24 and 25-30; these two categories were joint in second to last ranking. When the values are represented as real data it can be seen that out of the 22 respondents only 2 individuals were in the 16-24 category whilst a quantity of 9 individuals identified themselves as being between 41-50. This data illustrates a significant differential in the age of employees. 


\section{Please Specify Gender}

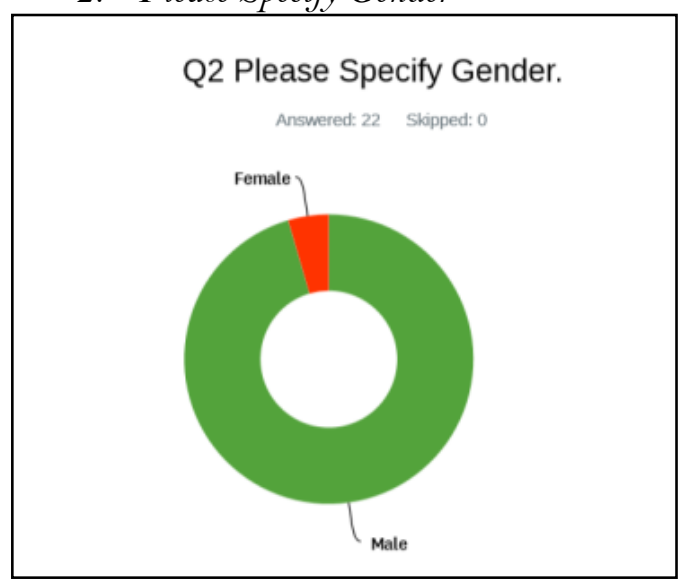

Figure 8. Gender Doughnut Chart

A qualitative demographic question, figure 9 revealed the severity of gender diversity issues within engineering. Out of the 22 respondents only 1 individual identified themselves as a female; to further demonstrate the inequality, the results have shown that this individual was not employed in a technical position.

3. Which Term Appears in Your Job Title?

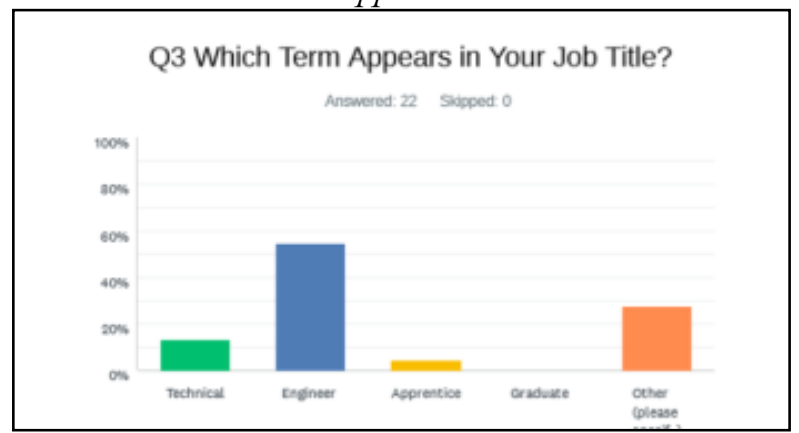

Figure 9. Job Title Vertical Bar Graph

As expected within manufacturing companies, close to $60 \%$ of the employees had the term 'engineer' within their job title. Unfortunately, the data shows only around $5 \%$ of the participants were employed as apprentices - this equates to one individual. Additionally, it can be seen none of the respondents were employed graduates. This indicates that there are minimal educational schemes in progress within the industry at the time of this survey, showing that efforts to aid the curbing of the skills gap are not currently the top priority within businesses.

\section{Please Indicate Your Educational Route}

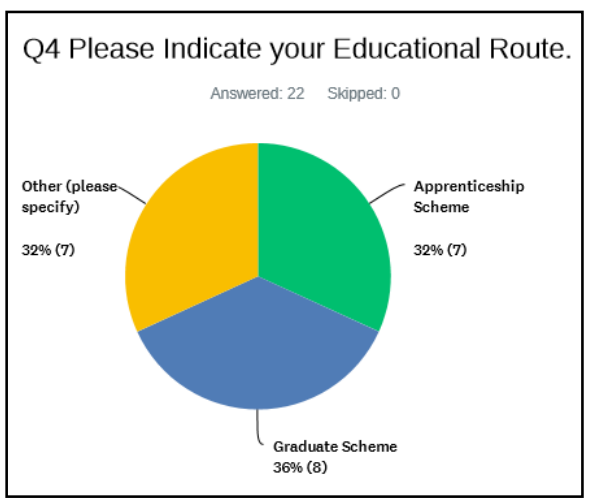

Figure 10. Education route pie chart

Figure 11 demonstrates that there was an equal split in how individuals had attained their education.

\section{What Qualifications do you Currently Hold?} From this question, an understanding can be gained on not only the specifics of what qualifications individuals hold, but additionally what the titles of these qualifications are. This gives the study a further insight into the variety of educational routes that contribute to pursuing a career as an engineer. Examples attained from the survey include

- BEng in Mechanical Engineering

- HNC in Mechanical Engineering

- City and guilds qualifications

- NVQs

\section{Please Indicate Your Experience Range (Years)}

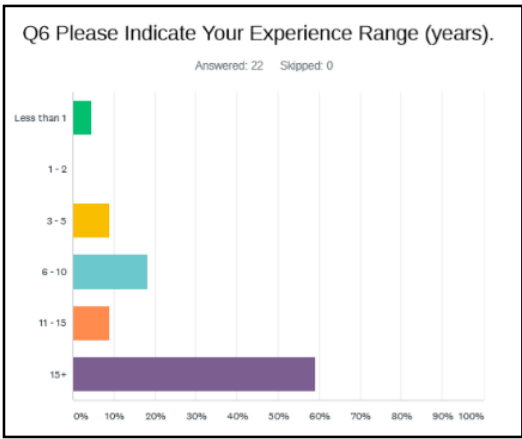

Figure 11. Experience range Horizontal Bar Chart

Figure 12 demonstrates the results obtained from this quantitative line of questioning. It can be seen that the highest band of experience was individuals in the $15+$ years range whilst the lowest was the $<1$ year range; with the 1-2 year range remaining empty. Ideally this graph should show have an exponential or linear progression. However, with the accepted knowledge of the presence of a skills gap, it would be expected that a parabolic curve type would be visible if plotted on a line graph. What this 
graph actually postulates, is evidence of a skills gap with the workforce (around 60\%) being in the $15+$ year category whilst there is a clear jump in experience with regards to the 1-2 year category.

\section{Do You Currently Hold a Managerial Position?}

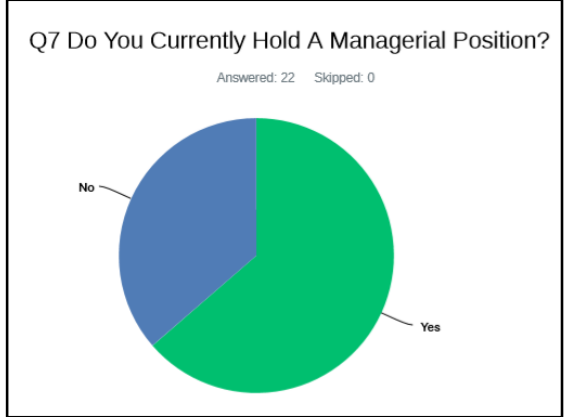

Figure 12. Managerial position pie chart

Figure 15 demonstrates that more individuals were employed as management than working employees. This could be a result of the number of respondents who undertook the survey, this could also be a true indication that there are more managerial positions within a company available than that of employed workers. This in turn could indicate the heavy presence of corporate structures in engineering.

\section{Indicate Your Preferred Pay Structure.}

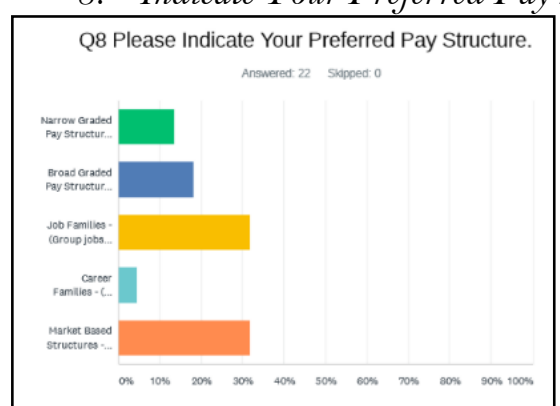

Figure 13. Pay structure Horizontal Bar Chart

Understanding the drivers and motivators of people looking to undertake a career in engineering can help entice younger people to it. Figure 14 shows two preferred payment structures, these are: Job families and Market Based Structures. These results indicate a desire for a more analytical foundation when specifying salaries.
9. Please rank in order of importance (one being the most important) which benefits would be most attractive for a career in engineering?

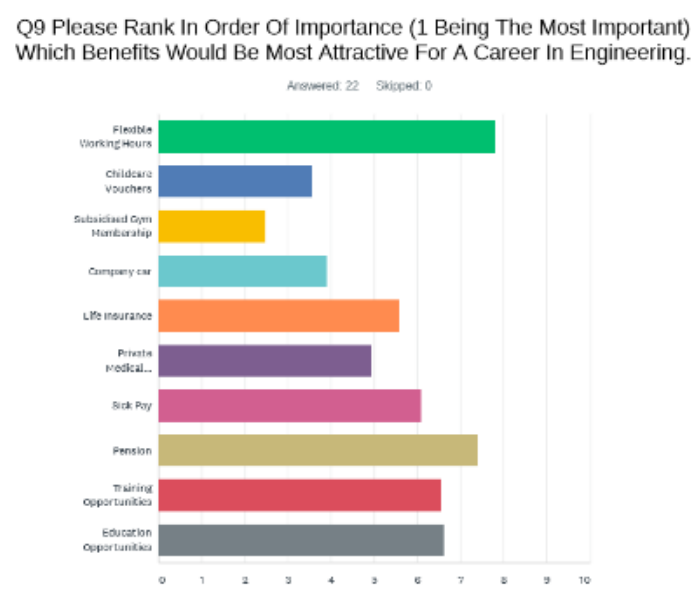

Figure 14. Benefits Horizontal Bar Chart

Figure 15 helps in understanding what kinds of changes the industry could make to the benefits they offer to prospective staff members. On scale of 0 to 10 , flexible working hours were ranked the highest. Secondly, individuals desired a pension scheme, and finally education opportunities. Summarised, this is as follows:

- Flexible Working Hours

- Pension Scheme

- Education Opportunities

The answers given to question 9 allow for the assumption that employed individuals in 2020 desire employment where their work is modelled around their life commitments rather than the reverse. Finally, the indication of educational opportunities as a third most appealing option demonstrates the desire for individuals to progress within their employed roles. 
10. Please rank in order of importance (one being the most important) which you feel is top priority?

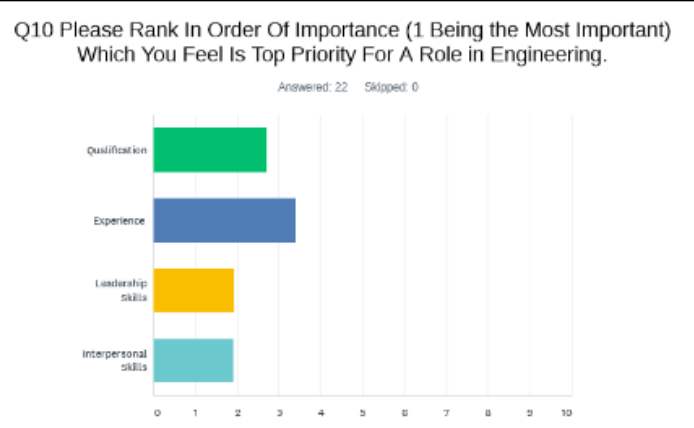

Figure 15. Skill priority Horizontal Bar Chart

Figure 16 indicates that experience is valued more than qualifications; an individual's qualification level is considered the second most important element when recruiting. This demonstrates that providing individual training with practical experience in engineering such as a placement year graduate scheme or apprenticeship scheme, increases a candidates' chance of employment.

11. What quantification of experience would you assign to an individual to consider them a competent engineer (years)?

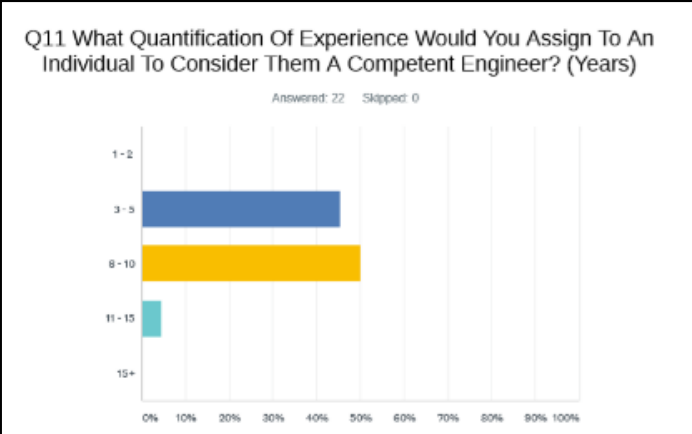

Figure 16. Experience Horizontal Bar Chart

When looking at the quantification of experience in years, figure 17 demonstrates that the industry feels that between 6-10 years' experience is adequate for an individual to be classified as a competent engineer.
12. How would you rate the education you received post-secondary education?

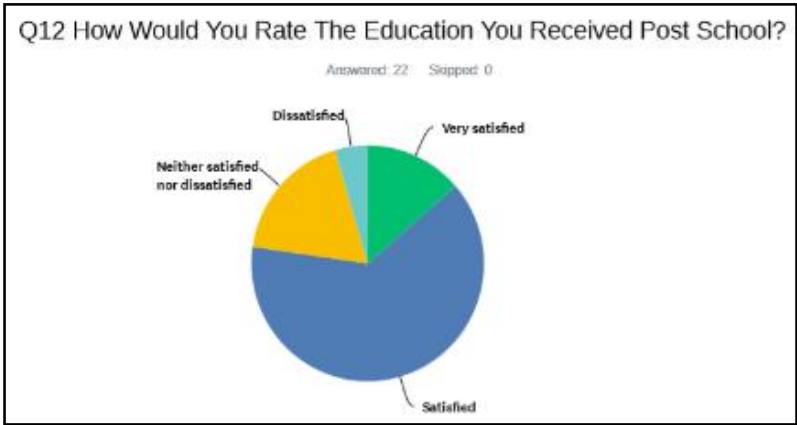

Figure 17. Education pie chart

The majority of respondents were satisfied with the education they received. These answers create a juxtaposition within this research project, indicating that the industry does not necessarily believe the education system is totally responsible for the lack of quality of engineers. Drawing a conclusion from this, it could be said that the reason the satisfied section was so popular was because the majority of the individuals who responded were educated between 1986 and 1995. Education has since undergone a huge digitalisation process. However, individuals in the 16-24 age category also indicated they were satisfied with the education they had received. Ultimately, due to the small sample size, a statistically valid conclusion cannot be drawn from these results alone.

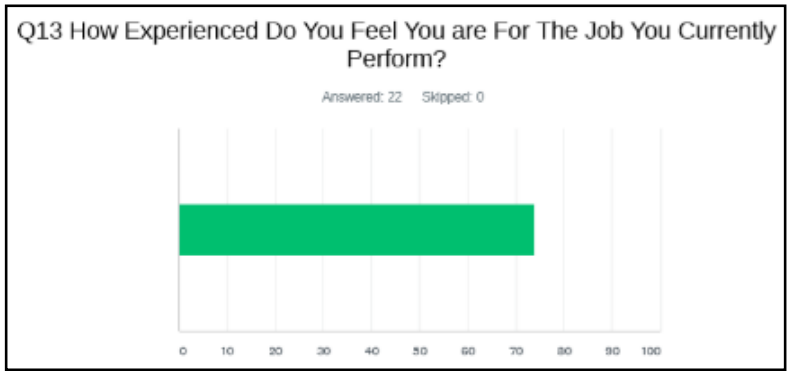

Figure 18. Experience Horizontal scale

\section{How would you rate the education you received post-secondary education?}

Given a scale of 0 to 100 , respondents were asked to rate their own experience. An average figure of around $72 \%$ was returned. From the data reviewed thus far it can be seen that a large majority of the respondents were aged above 40 with over 15 years' experience in engineering - therefore, it was anticipated that the value pictured in figure 19 would be higher. 
14. How qualified do you feel you are for the job role you currently perform?

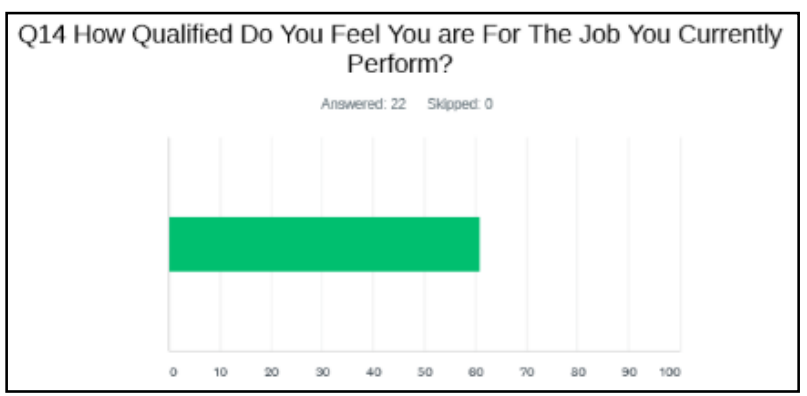

Figure 19. Qualification Horizontal scale

Figure 20 demonstrates the results returned when respondents were asked to rate their qualifications in question fourteen. It can be seen that this figure is lower at around $60 \%$, which lends itself to the objectives of this study. This is because the two charts above reinforce the answers given in questions nine and ten, in showing that the industry does value an individual's experience more than their qualifications - but it also indicates that individuals are not deterred from recognising educational improvements.

15. Are there any changes you would suggest to the post-secondary education system for training engineers within the UK?

Question 15 allows an understanding of the specific changes industry would like to see from the education system. From this list it can be seen that 6 out of the 22 respondents did not feel there were any changes to be made. However, when looking at the qualitative data provided in the other responses it can be seen that there is a common change that the engineering industry desires. This change is that of more work-based practical experience being integrated into the training. It is indicated that this can either be done via increasing the amount of apprenticeships available or through reforming the graduate schemes to incorporate more practical education. Some of the feedback is as follows

- "More apprenticeships available"

- "Better paid apprenticeships...make it the most attractive of the alternatives"

- "More work-based placements"

- The UK has not invested in manufacturing, as such I believe there isn't as much desire for individuals to get into engineering as a career.
16. Do you believe there is a skills gap in your sector within the UK?

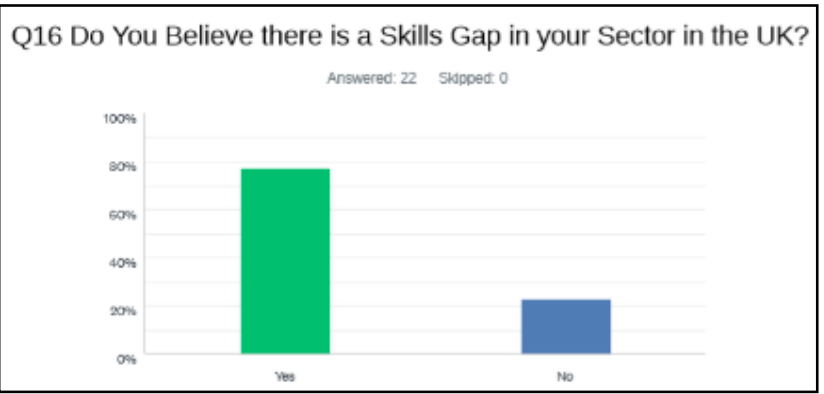

Figure 20. Q16 Vertical Bar Graph

17. Do you believe that there is a deficit of engineering principle as a result of the UK skills gap?

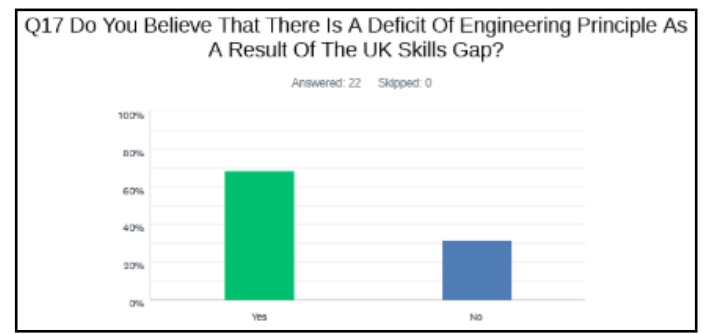

Figure 21. Q17 Vertical Bar Graph

18. How severe would you describe the UK skills gap?

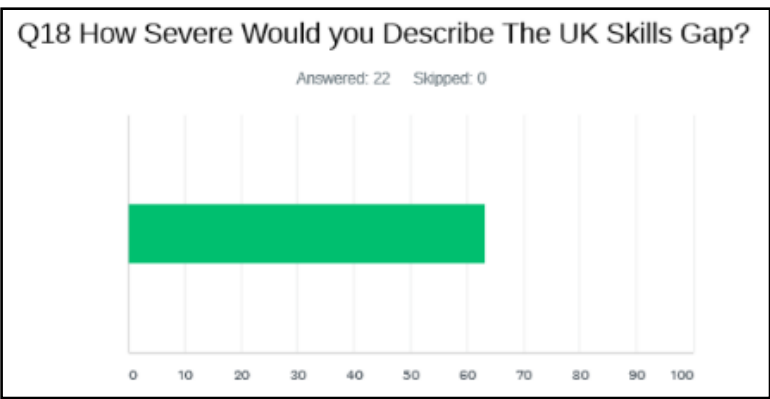

Figure 22. Q18 Vertical Bar Graph

Questions 16, 17 and 18 all assess the same element within the survey and deliver a similar outcome. These three questions reinforce that the purpose and subject matter of this survey are important considerations within the industry, with individuals indicating a skills gap is present within the UK in addition to the prospect that the quality of engineers is being compromised. 


\section{How would define you the noun "Engineer"?}

Question 19 shows a common problem encountered in engineering that can be linked to the issue of incorrect training; the definition of the term "Engineer" is not yet universally agreed upon in the UK. Some of the feedback is as follows:

- "One who invents, designs, builds, tests or maintains equipment, structures or machines; using scientific principles to do so, along with their own experience and that of their peers. The process of learning and review of their knowledge never stops for an Engineer".

- "too often used for non-specific meanings it should be same as a professional such as 'doctor' or 'lawyer"

- "Skilled in design"

- "Someone who provides working solutions to technical problems."

- "An Engineer is someone who uses scientific knowledge to design, construct and maintain engines and machines or structures."

- "Holder of a BEng (Hons)."

- "Technical Knowledge to solve problems within a team".

- "Multi-skilled personnel".

- "Able to design practical solutions to physical problems."

- "A problem solver."

One thing that can be deduced from the answers is that there is no specific standard definition of the term "engineer" - however, individuals expressed that an engineer should be someone who can apply a level of intelligent practical thinking and an alternative manner to solve problems.

\section{Discussion}

When attempting to define what constitutes a competent, balanced engineer, the results yielded directly from industry reveal that an engineer should have more experience than qualifications. Additionally, this experience should be no less than six years but is not required to be any more than ten years. Finally, answers to question 19 offer us an understanding of what an engineer should be. When reviewed, the general consensus was that an engineer "is an individual who applies methodical practical and technical knowledge to create theoretical and practical solutions to complex problems". From the answers to question 15, it can be seen that to aid in increasing the quality of engineers, the respondents suggestions focused on improvements to the post-secondary educational system for engineers. Mainly this involved suggesting more apprenticeships be made available, and in particular indicating improvements to the apprenticeship system to make them more appealing such as higher pay for apprentices would be a suitable change amongst others. Additionally, it was also suggested that more practical and workplace-relevant skills should be taught at undergraduate level qualifications with the possibility of providing free education as a consideration. Furthermore, based on research performed in the literature review, it could also be proposed that better graduate schemes from employers need to be offered.

The survey revealed that individuals desired other changes within the industry to make a career in engineering more appealing. These changes would have a similar impact on apprenticeships in the field. Results from Question 8 illustrate that a company utilising either a market-based pay structure or a job family method of pay would be more desirable behind quantification of their salary. Question 9 indicates that the top three in work benefits are: flexible working hours, a pension scheme and training/education opportunities; these factors would therefore be part of what might encourage an individual to undertake a career in engineering. It can be postulated that if these benefits were also extended and advertised to apprentices then this would encourage more people to peruse an engineering apprenticeship. For example, if an understanding of the further education available in addition to a suitable training plan for younger engineers is offered, then this could encourage people to commence an apprenticeship with the understanding that the opportunities available are not limited.

Multitudinous suggestions for future studies of this topic are available, many of which do not focus specifically on the subject matter investigated in this project. For the future of this specific subject matter "Is there a deficit of engineering principle as a result of the UK skills gap", the following areas of focus are suggested as being worthy of further research:

- Interview: the interview from this survey, which unfortunately could not take place, should be performed as an extension of this report.

- Further research: postgraduate research should be performed allowing more focus to 
be given to specific elements of the study, in addition to further investigation.

- Case study: observe an individual from leaving school, undertaking their apprenticeship until completion. If the individual chooses to perform further education beyond this, then this should also be observed.

- Case study: observe an individual from the beginning of their undergraduate education through to completion of this and one year of employment after.

- Advanced survey performed countrywide with manufacturing businesses and the cooperation of institutes such as the IET or IMECH

Finally, in 2019, at the start of this study, the relevance of the potential outcomes on modern society were not fully comprehendible. As the covid-19 pandemic of 2020 unravelled while this study was carried out and then submitted, the conclusions arrived at became even more poignant in nature. If this current UK political, societal and financial climate is considered and likened in a manner that was experienced just after World War 2 (as briefly discussed in this study), then the reemergence of engineering and manufacturing is of paramount importance to help rebuild the British economy. Simply put, the UK will rely on young qualified, competent and passionate engineers to aid in the reconstruction of the UK economy in a post pandemic climate. Young engineers who currently are being neglected by industry, education and the government.

\section{Conclusion}

Observing the results attained from the survey it can be seen that whilst a defined path of correction for the education of engineers cannot be fully established from this study alone, guidance can be proposed based on the outcomes of the survey. Data from the workplace survey shows that professionals within the industry do believe there is UK skills gap in addition to a shortage of engineering principle as a result of the gap. These conclusions were attained from the data revealed in answers to questions $1,2,3,16,17$ and 18 which clearly demonstrate the opinion of respondents. The study also established initial tasks that can be performed to further investigate the subject matter.

To conclude this study, it can be said that at face value the results yielded are insignificant when considered with respect of the small sample size of professionals used, however this study provides a new branch of work to be investigated when understanding how the UK skills gap affected the engineering and manufacturing industry.

\section{$\underline{\text { References }}$}

Beatty, C., Fothergill, S. \& Powell, R. (2007). Twenty years on: has the economy of the UK coalfields recovered? Environmental Planning A, 39, 16541675. Retrieved from https://www.channel4.com/media/c4news/pdf/coalfields.pdf

Coman, J. (April 14, 2013). Margaret Thatcher: 20 ways that she changed Britain. The Guardian.

Retrieved from

https://www.theguardian.com/politics/2013/apr/14/margaret-thatcher-20-changesbritain

In Cambridge Dictionary. (2020). Engineer. Retrieved from https://dictionary.cambridge.org/dictionary/english/engineer

Engineering UK (2018). Synopsis and recommendations. Retrieved from https://www.engineeringuk.com/media- 
/1576/7444_enguk18_synopsis_standalone_aw.pdf

Gov.uk. (2020). Employing an apprentice. Retrieved from https://www.gov.uk/take-on-anapprentice/get-funding

History.com. (2009). Marshall Plan. Retrieved from https://www.history.com/topics/world-warii/marshall-plan-1

Kitson, M., \& Michie, J. (2014). The de-industrial revolution: the rise and fall of UK manufacturing, 1870-2010. Retrieved from https://www.josharcher.uk/static/files/2013/industrial-performance-1870-2010.pdf

Machin, S., \& Vignoles, A. (2006). Education policy in the UK. Retrieved from

http://cee.lse.ac.uk/ceedps/ceedp57.pdf

Matthews, C. (2012). Engineers data book IMECHE (4th Ed.). West Sussex: John Wiley and Sons Ltd.

Northern Mine Research Society. (2020). Collieries of the British Isles. Retrieved from https://www.nmrs.org.uk/mines-map/coalmining-in-the-british-isles/collieries-of-thebritish-isles/

Office of National Statistics. (2018). Long-term trends in UK employment: 1861 to 2018 . Retrieved from https://www.ons.gov.uk/economynationalaccounts/uksectoraccounts/compendium/economicreview/april2019/longtermtrendsinukemployment 1861 to2018

Opensecrets.org. (2020). Interest groups. Retrieved from https://www.opensecrets.org/industries/slist.php

Osborne, A. (April 8, 2013). Margaret Thatcher: one policy that led to more than 50 companies being sold or privatised. The Telegraph. Retrieved from https://www.telegraph.co.uk/finance/comment/alistair-osborne/9980292/margaretthatcher-one-policy-that-led-to-more-than-50companies-being-sold-or-privatised.html

Oxford University press (2019). Engineer. Oxford learner's dictionary. Retrieved from https://www.oxfordlearnersdictionaries-.com/definition/english/engineer_2
Pettinger, T. (2017). UK post-war economic boom and reduction in debt. Economics Help. Retrieved from https://www.economicshelp.org/blog/1 1697/debt/post-war-boom/

Royal Academy of Engineering. (2018). Engineering education systems that are fit for the future. Retrieved from https://www.raeng.org.uk/publications/other/engineering-educationsystems-that-are-fit-for-the

Royal Academy of Engineering. (2012). Achieving excellence in engineering education: the ingredients of successful change. Retrieved from https://www.raeng.org.uk/publications/reports/achieving-excellence-inengineering-education

The Manufacturer. (2019). UK manufacturing statistics. Retrieved from https://www.themanufacturer.com/ukmanufacturing-statistics/ 